\title{
Chemoembolization Combined with Pravastatin Improves Survival in Patients with Hepatocellular Carcinoma
}

\author{
Hannah Graf ${ }^{a}$ Christoph Jüngst ${ }^{g} \quad$ Gundula Straub $^{a}$ Selin Dogan ${ }^{f}$ \\ Ralf-Thorsten Hoffmann ${ }^{b}$ Tobias Jakobs ${ }^{b}$ Maximilian Reiser ${ }^{b}$ \\ Tobias Waggershauser $^{b}$ Thomas Helmberger ${ }^{d} \quad$ Andreas Walter $^{\mathrm{e}} \quad$ Autar Walli $^{\mathrm{c}}$ \\ Dietrich Seidel $^{c}$ Burkhard Göke ${ }^{a}$ Dieter Jüngst ${ }^{a}$
}

Departments of a Medicine II, ${ }^{b}$ Radiology and ${ }^{c}$ Clinical Chemistry, Klinikum Grosshadern, Ludwig Maximilian University, ${ }^{\mathrm{d}}$ Department of Radiology, Klinikum Bogenhausen, and ${ }^{\mathrm{e}}$ Department of Surgery, Klinikum der Barmherzigen Brüder, Munich, and ${ }^{\mathrm{f}}$ Department of Internal Medicine, Klinikum Landshut, Landshut, Germany; gDivision of Clinical Pharmacology and Toxicology, University Hospital Zurich, Zurich, Switzerland

\section{Key Words}

Pravastatin - Hepatocellular carcinoma •

Chemoembolization

\begin{abstract}
Background/Aims: Pravastatin, a 3-hydroxy-3-methylglutaryl coenzyme A reductase inhibitor, has been shown to inhibit growth and to induce apoptosis in human hepatocellular carcinoma (HCC) cells. However, the potential benefit of pravastatin in HCC patients has still not been characterized, which prompted us to test the efficacy of pravastatin in patients with advanced HCC. Methods: We investigated prospectively a cohort of 183 HCC patients who had been selected for palliative treatment by transarterial chemoembolization (TACE). Fifty-two patients received TACE combined with pravastatin (20-40 mg/day) and 131 patients received chemoembolization alone. Six independent predictors of survival according to the Vienna survival model for HCC were equally distributed in both groups. Results: During the observation period of up to 5 years, 31 (23.7\%) out of 131 patients treated by TACE alone and 19 (36.5\%) out of 52 patients treated by TACE and pravastatin survived. Median
\end{abstract}

survival was significantly longer in HCC patients treated by TACE and pravastatin (20.9 months, 95\% Cl 15.5-26.3, $\mathrm{p}=$ $0.003)$ than in HCC patients treated by TACE alone (12.0 months, 95\% Cl 10.3-13.7). Conclusion: Combined treatment of chemoembolization and pravastatin improves survival of patients with advanced HCC in comparison to patients receiving chemoembolization alone.

Copyright $\odot 2008$ S. Karger AG, Basel

Hepatocellular carcinoma (HCC) is one of the most frequent malignancies and annually accounts for as many as 1 million deaths worldwide [1-4]. Most patients have 2 diseases - chronic liver disease and HCC - and complex interactions between them have major implications for diagnosis, prognosis and the management of HCC.

The clinical course of patients with HCC is determined by both liver function and the extent of the HCC. Transarterial chemoembolization (TACE) is a minimally invasive procedure that has a demonstrated ability to reduce systemic toxicity, increase local effects and improve overall therapeutic results, particularly in the treatment of unresectable hepatocellular carcinoma [5-10].

\section{KARGER}

Fax +41613061234 E-Mail karger@karger.ch www.karger.com
(C) 2008 S. Karger AG, Base

$0012-2823 / 08 / 0781-0034 \$ 24.50 / 0$

Accessible online at:

www.karger.com/dig
Dieter Jüngst, MD

Department of Medicine II, Klinikum Grosshadern

Ludwig Maximilian University, Marchioninistrasse 15

DE-81377 München (Germany), Tel. +49 897095 2376, Fax +49 8970955374

E-Mail Dieter.Juengst@med.uni-muenchen.de 
In addition to their cholesterol-lowering effects, statins such as fluvastatin and pravastatin inhibit tumor cell growth [11-14]. More recently it was demonstrated that pravastatin reduces progression and limits metastatic diffusion in a rat model of very aggressive HCC [15]. A clinical study by Kawata et al. [16], the only one conducted so far, showed that pravastatin prolongs survival of patients with advanced HCC when applied after treatment with TACE and oral 5-fluorouracil. Nevertheless, the benefit of pravastatin in HCC patients has still not been characterized, which prompted us to test the efficacy of pravastatin in a large cohort of patients with advanced HCC who had been selected for TACE.

\section{Patients and Methods}

Our prospective cohort included 183 HCC patients (149 males and 34 females, mean age $64 \pm 10$ years) who were diagnosed and staged in our institution between 2003 and 2008. Patients with early HCC ( 1 nodule $<5 \mathrm{~cm}$ or 3 nodules $<3 \mathrm{~cm}$ each) and impaired liver function who were considered for orthotopic liver transplantation were not evaluated in this investigation.

To address the problem of selection bias we determined in the cohort of 183 HCC-patients 6 independent predictors of survival. These included bilirubin ( $>2 \mathrm{mg} / \mathrm{dl})$, portal vein thrombosis, prothrombin time $(<70 \%), \alpha$-fetoprotein (AFP, $>125 \mathrm{kU} / \mathrm{l}$ ), tumor mass $>50 \%$ and enlarged lymph nodes, according to the Vienna survival model for HCC (VISUM-HCC) [17].

Prior to therapy, 138 HCC patients presented with VISUM stage 1 ( $0-2$ points), while 30 patients were classified as stage 2 (3 points) and 15 patients as stage 3 (4-6 points).

All patients selected for TACE had advanced HCC and did not fit into the surgical criteria either for resection (due to bilateral disease, inoperability due to cardiopulmonary risk factors, unresectability due to proximity of the tumors to large vessels or impaired liver function) or liver transplantation (according to the Milan criteria: fewer than 3 nodules $<3 \mathrm{~cm}$ in diameter or a single $\mathrm{HCC}<5 \mathrm{~cm}$ in diameter) or for combined treatment with chemoembolization and radiofrequency ablation (tumor size $<5 \mathrm{~cm}$, fewer than 4-5 tumor nodules, no significant extrahepatic spread).

Disease extension was assessed using ultrasound, computed tomography (CT) and magnetic resonance imaging.

Diagnosis of HCC was confirmed via needle biopsy or via radiological criteria (2 coincident imaging techniques) or combined criteria (1 imaging technique associated with elevated AFP levels according to the Barcelona EASL Conference 2000 [18]). Written informed consent was obtained from each patient and the study protocol conformed to the ethical guidelines of the 1975 Declaration of Helsinki, as reflected in a priori approval by the institutional review committee.

Treatment Procedures

Transarterial Chemoembolization. Patients not suitable for surgery or combined treatment with TACE and radiofrequency ablation were considered for chemoembolization alone. Patients with multifocal large ( $>8 \mathrm{~cm}$ tumor nodules) and diffuse growing tumors were not included for TACE.

All TACE procedures were performed under angiographic control (Multistar TOP and Axiom Artis dTA, Siemens, Munich, Germany) and under local anesthesia. After inserting a 4-Fr pigtail catheter into the femoral artery via a microincision in the groin, a panviscerography was performed to detect potential aberrant or additional hepatic and possibly tumor-feeding arteries. After identifying the tumor-feeding arteries, a 4-Fr catheter (e.g. cobra configuration) for selective use or a superselective microcatheter, which could be placed through the primary 4-Fr catheter, were directed as close as possible to the tumor-feeding vessels. The embolizing moiety was prepared by extensive mixing between 2 syringes, typically 3-5 ml lipiodol, microparticles of $150-$ $500 \mu \mathrm{m}$ (e.g. Contour SE ${ }^{\circledR}$, Boston Scientific, Ratingen, Germany) and farmorubicin $(1 \mathrm{mg} / \mathrm{kg}$ b.w.). The embolizing agent was then injected slowly under fluoroscopic control to avoid retrograde embolization of nontarget areas due to back spill. As soon as stasis within the tumor vessels occurred, the injection was stopped. Treatment was terminated if, over 5-10 min, a flow within the tumor vessels was no longer detectable. Otherwise another injection was performed. In cases of several main feeders these vessels were treated subsequently.

One day after the procedure a baseline CT was performed to document the storage of the embolizing agent within the tumor. Follow-up studies by triphasic (native, arterial and portal-venous) contrast-enhanced CT were performed incorporating the general clinical situation of the patient $6-12$ weeks after the initial procedure, and a new TACE was performed if there were signs of 'destorage' with revascularization of the treated tumor, or if new tumors were detected.

Systemic Therapy with Pravastatin. Fifty-two HCC patients (41 men and 11 women, mean age $66 \pm 10$ years) received 20-40 mg pravastatin as a single dose daily in addition to chemoembolization.

\section{Follow-Up and Statistical Analysis}

Survival was set as the primary endpoint of the study. Followup every 3-6 months was computed as starting from the beginning of the treatment and was maintained until death or the last visit before March 2008. Patients received clinical examination, blood analysis including AFP and imaging techniques (ultrasound, spiral CT or magnetic resonance imaging alternatively). Upon detection of treatment failure or recurrence, patients were considered for new treatment sessions.

Probability curves obtained via the Kaplan-Meier method were compared using the log rank test, and for group comparisons the $\chi^{2}$ and Mann-Whitney tests were performed.

Calculations were done with SPSS package (SPSS Inc., Chicago, Ill., USA) and the level of significance was set at $\mathrm{p}<0.05$.

\section{Results}

Table 1 depicts the characteristics of the 2 groups of HCC patients. No significant difference between the 2 groups was detected concerning age, sex, etiology of liver cirrhosis, VISUM score, AFP, presence of portal-vein 
Table 1. Characteristics of 183 HCC patients prior to treatment with TACE alone or TACE and pravastatin

\begin{tabular}{|c|c|c|c|}
\hline Variables & $\begin{array}{l}\text { TACE } \\
\text { alone }\end{array}$ & $\begin{array}{l}\text { TACE and } \\
\text { pravastatin }\end{array}$ & $\mathrm{p}$ \\
\hline Age & $63 \pm 10$ & $66 \pm 10$ & 0.101 \\
\hline $\operatorname{Sex}(M / F)$ & $108 / 23$ & $41 / 11$ & 0.574 \\
\hline \multicolumn{4}{|l|}{ Etiology } \\
\hline $\mathrm{HCV}$ & 32 & 9 & \\
\hline $\mathrm{HBV}$ & 10 & 3 & \\
\hline Alcohol & 42 & 17 & \\
\hline Other & 36 & 19 & \\
\hline Mixed & 11 & 4 & \\
\hline VISUM score & & & 0.239 \\
\hline $0-2$ & 102 & 36 & \\
\hline 3 & 19 & 11 & \\
\hline $4-6$ & 10 & 5 & \\
\hline Bilirubin, mg/dl & $1.8 \pm 1.4$ & $1.6 \pm 1.2$ & 0.284 \\
\hline Bilirubin & & & 0.691 \\
\hline$\leq 2 \mathrm{mg} / \mathrm{dl}$ & 97 & 37 & \\
\hline$>2 \mathrm{mg} / \mathrm{dl}$ & 34 & 15 & \\
\hline Prothrombin act, $\%$ & $75.1 \pm 14.4$ & $76.6 \pm 14.0$ & 0.590 \\
\hline Prothrombin act & & & 0.797 \\
\hline$>70 \%$ & 83 & 34 & \\
\hline$\leq 70 \%$ & 48 & 18 & \\
\hline AFP & & & 0.565 \\
\hline$\leq 125 \mathrm{kU} / 1$ & 81 & 30 & \\
\hline$>125 \mathrm{kU} / \mathrm{l}$ & 50 & 22 & \\
\hline Portal vein thrombosis & & & 0.741 \\
\hline Yes & 13 & 4 & \\
\hline No & 118 & 48 & \\
\hline Enlarged lymph nodes & & & 0.016 \\
\hline Yes & 27 & 20 & \\
\hline No & 104 & 32 & \\
\hline Tumor size & & & 0.960 \\
\hline$\leq 50 \%$ & 70 & 28 & \\
\hline$>50 \%$ & 61 & 24 & \\
\hline Number of TACE & $4.2 \pm 3.8$ & $4.2 \pm 2.7$ & \\
\hline Median survival time, months & 12.0 & 20.9 & \\
\hline $95 \% \mathrm{CI}$ & $10.3-13.7$ & $15.5-26.3$ & \\
\hline
\end{tabular}

$\mathrm{HBV}=$ Hepatitis $\mathrm{B}$ virus; $\mathrm{HCV}=$ hepatitis $\mathrm{C}$ virus.

thrombosis, bilirubin levels, prothrombin times and the number of TACE treatments. Enlarged perihepatic lymph nodes were significantly $(\mathrm{p}=0.016)$ more frequent in HCC patients treated with TACE and pravastatin. Furthermore, table 1 illustrates survival time (median and 95\% CI) in the 183 patients with HCC who received TACE alone or TACE combined with pravastatin. During the observation period of up to 5 years, 31 (23.7\%) out of 131 patients treated by TACE alone and 19 (36.5\%) out of 52 patients treated by TACE and pravastatin survived.

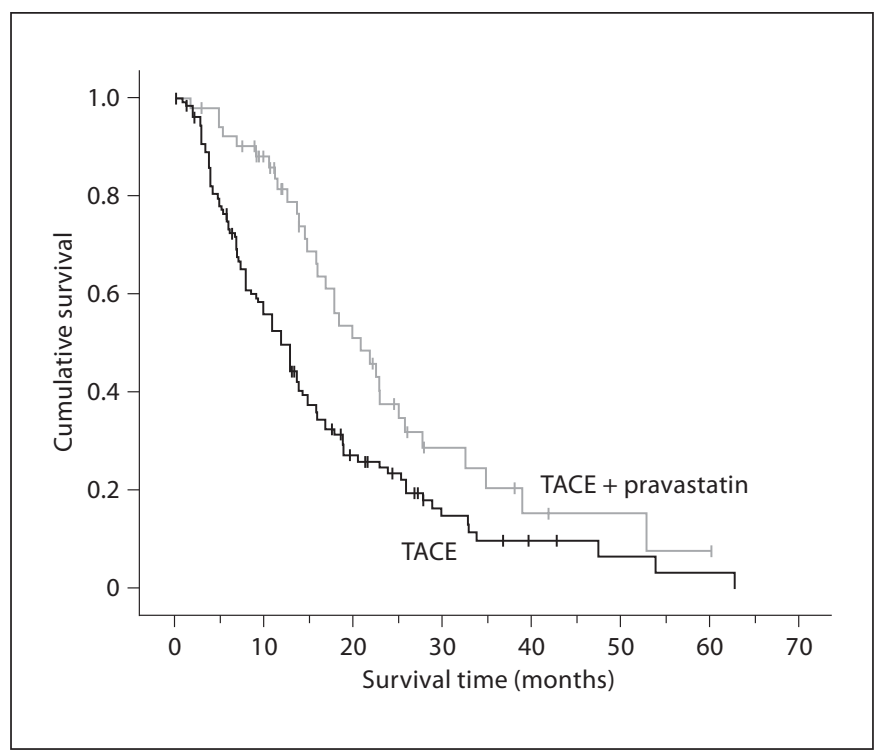

Fig. 1. Survival rates determined by Kaplan-Meier of HCC patients treated by combined TACE and pravastatin $(n=52)$ or TACE alone $(n=131)$. Statistical evaluation by log rank test showed an improved survival of patients treated by TACE and pravastatin compared to TACE alone $(\mathrm{p}=0.003)$.

Statistical analysis showed a significantly $(\mathrm{p}=0.003)$ improved survival time in the subgroup of patients treated with chemoembolization and pravastatin (median 20.9 months, 95\% CI 15.5-26.3) compared to patients treated with chemoembolization alone (median 12.0 months, 95\% CI 10.3-13.7).

Kaplan-Meier plots of the 2 groups of HCC patients are illustrated in figure 1 and demonstrate the marked survival benefit to HCC patients of treatment with chemoembolization combined with pravastatin as compared to chemoembolization alone.

\section{Discussion}

The management of HCC has improved in recent years. However, many treatments for HCC have only limited impact on outcome since most patients with HCC suffer from 2 diseases: chronic liver disease, usually at the stage of cirrhosis, and HCC [19]. Thus, both the extent of HCC and the grade of liver dysfunction affect the prognosis of HCC patients. Therefore, most prognostic scores include parameters of liver function.

An independent evaluation of prognostic scores in a Central European cohort of patients with HCC has been 
presented recently [20]. The Child-Turcotte-Pugh score, Okuda score, VISUM-HCC score, Chevret score, Barcelona clinic liver cancer classification and cancer of the liver Italian program score were calculated. All scores performed similarly to the Okuda score in the receiver operating characteristic analysis.

In our prospective study we used the new VISUMHCC survival model [17] to characterize the cohorts of patients who had received treatment by chemoembolization alone or chemoembolization and pravastatin. The 6 independent predictors of survival according to VISUMHCC were equally distributed in both groups (table 1). However, the main problem of our study is that it is not randomized or blinded. Indeed, most patients receiving the additional application of pravastatin were selected by the principal investigators (B.G. and D.J.) after admission to the hospital. They represent a cohort of patients with advanced HCC suitable for treatment by transarterial chemoembolization. As illustrated in table 1, the 6 independent predictors of survival according to VISUM-HCC were equally distributed between patients receiving TACE alone or combined with pravastatin. Thus, it is not likely that a selection bias has affected the outcome of the study (survival time).

The success of chemoembolization relies on the fact that HCC derives its blood supply predominantly from the hepatic artery, whereas the surrounding liver receives both portal and arterial blood. Chemoembolization requires catheterization of the segmental hepatic artery supplying the tumor and performance of an arteriogram.

Chemotherapeutic agents are then injected intra-arterially and the hepatic artery is then occluded by injection of material to obstruct the flow $[6,7,21]$.

The theoretical benefits of this approach include delivery of a high concentration of chemotherapy to the tumor, a marked increase in contact time between drugs and tumor cells and high rates of first-pass extraction. Thus, the drugs are concentrated in the liver and tumor while systemic effects are minimized. However, chemoembolization is generally considered as palliative treatment because it does not achieve complete necrosis of the tumor.

Thus, our patients treated with chemoembolization alone showed a less favorable prognosis in the long term. As illustrated in figure 1, within the first year the survival is about $50 \%$, but only a few patients survived to the end of the 3-year follow-up.

Drug resistance is one of the major problems of chemotherapy, which causes treatment failure and leads to progressive disease [22]. Potential mechanisms of resistance to cytotoxic drugs include the activation of the Ras/ Raf/MEK/ERK signal transduction cascade [11] and the increase of cholesterol levels in cancer cells $[23,24]$. The enzyme 3-hydroxy-3-methylglutaryl coenzyme-A reductase (HMG-CoAR) is known to catalyze, the rate-limiting step in the mevalonate pathway, leading to the production of isoprenoids. Isoprenoids are involved both in the activation of Ras and in cholesterol synthesis [25]. Thus, HMG-CoAR is a rational molecular target for innovative antineoplastic treatment of HCC.

In addition to their cholesterol-lowering effects, statins such as fluvastatin and pravastatin inhibit tumor cell growth [11-14]. Statins have also been shown to synergistically enhance the effects of chemotherapy and to overcome chemoresistance [26-33]. Moreover, morbid obesity has been shown to be associated with increased cholesterol and HMG-CoAR levels and with liver cancer [34, 35]. Accordingly, HMG-CoAR inhibition by pravastatin prolonged the survival of patients with advanced HCC in a randomized clinical trial [16].

Several preclinical trials confirm an anticancer efficacy of statins, investigating the mechanisms leading to growth inhibition [36]. In a recent study, Sutter et al. [22] showed that HMG-CoAR inhibitors decreased the proliferation of HCC cells by inducing apoptosis and cell cycle arrest. The authors suggest that the inhibition of HMGCoAR by statins is a promising novel approach for the treatment of HCC that warrants further evaluation. This has been done in our study and our data show that patients with advanced HCC have a more favorable longterm survival if combined treatment with chemoembolization and pravastatin is administered. These results are in accordance with the previous randomized controlled trial and support a wider application of pravastatin in HCC patients selected for chemoembolization.

\section{Acknowledgements}

The authors are grateful to Birgit Eberlein and Viera Stefanek for secretarial help. Parts of the data presented here were included in the MD thesis of H.G. This paper is dedicated to Gustav Paumgartner on the occasion of his 75th birthday. 


\section{References}

1 Bosch FX, Ribes J, Borras J: Epidemiology of primary liver cancer. Semin Liver Dis 1999; 19:271-285.

2 Befeler AS, di Bisceglie AM: Hepatocellular carcinoma: diagnosis and treatment. Gastroenterology 2002;122:1609-1619.

3 Llovet JM, Burroughs A, Bruix J: Hepatocellular carcinoma. Lancet 2003;362:19071917.

4 Kim WR, Gores GJ, Benson JT, Therneau TM, Melton LJ III: Mortality and hospital utilization for hepatocellular carcinoma in the United States. Gastroenterology 2005; 129:486-493.

5 Groupe d'Etude et de Traitement du HCC: A comparison of lipiodol chemoembolization and conservative treatment for unresectable HCC. N Engl J Med 1995;332:1256-1261.

6 Pelletier G, Ducreux M, Gay F, Luboinski M, Hagege H, Dao T, van Steenbergen W, Buffet C, Rougier P, Adler M, Pignon JP, Roche A: Treatment of unresectable hepatocellular carcinoma with lipiodol chemoembolization: a multicenter randomized trial. Groupe CHC. J Hepatol 1998;29:129-134.

7 Bruix J, Llovet JM, Castells A, Montana X, Bru C, Ayuso MC, Vilana R, Rodes J: Transarterial embolization versus symptomatic treatment in patients with advanced hepatocellular carcinoma: results of a randomized, controlled trial in a single institution. Hepatology 1998;27:1578-1583.

8 Llovet JM, Real MI, Montana X, Planas R, Coll S, Aponte J, Ayuso C, Sala M, Muchart J, Sola R, Rodes J, Bruix J; Barcelona Liver Cancer Group: Arterial embolisation or chemoembolisation versus symptomatic treatment in patients with unresectable hepatocellular carcinoma: a randomised controlled trial. Lancet 2002;359:1734-1739.

9 Llovet JM, Bruix J: Systematic review of randomized trials for unresectable hepatocellular carcinoma: chemoembolization improves survival. Hepatology 2003;37:429-442.

10 Takayasu K, Arii S, Ikai I, Omata M, Okita K, Ichida T, Matsuyama Y, Nakanuma Y, Kojiro M, Makuuchi M, Yamaoka Y; Liver Cancer Study Group of Japan: Prospective cohort study of transarterial chemoembolization for unresectable hepatocellular carcinoma in 8,510 patients. Gastroenterology 2006;131: 461-469.

11 Wong WW, Tan MM, Xia Z, Dimitroulakos J, Minden MD, Penn LZ: Cerivastatin triggers tumor-specific apoptosis with higher efficacy than lovastatin. Clin Cancer Res 2001; 7:2067-2075

12 Gebhardt A, Niendorf A: Effects of pravastatin, a hydroxymethylglutaryl-CoA reductase inhibitor, on two human tumour cell lines. J Cancer Res Clin Oncol 1995;121:343349.

13 Kawata S, Nagase T, Yamasaki E, Ishiguro H, Matsuzawa Y: Modulation of the mevalonate pathway and cell growth by pravastatin and D-limonene in a human hepatoma cell line (Hep G2). Br J Cancer 1994;69:1015-1020.

14 Paragh G, Kertai P, Kovacs P, Paragh G Jr, Fulop P, Foris G: HMG CoA reductase inhibitor fluvastatin arrests the development of implanted hepatocarcinoma in rats. Anticancer Res 2003;23:3949-3954.

15 Taras D, Blanc JF, Rullier A, Dugot-Senant N, Laurendeau I, Vidaud M, Rosenbaum J: Pravastatin reduces lung metastasis of rat hepatocellular carcinoma via a coordinated decrease of MMP expression and activity. J Hepatol 2007;46:69-76.

16 Kawata S, Yamasaki E, Nagase T, Inui Y, Ito N, Matsuda Y, Inada M, Tamura S, Noda S, Imai Y, Matsuzawa Y: Effect of pravastatin on survival in patients with advanced hepatocellular carcinoma: a randomized controlled trial. Br J Cancer 2001;84:886-891.

17 Schöniger-Hekele M, Müller C, Kutilek M, Oesterreicher C, Ferenci P, Gangl A: Hepatocellular carcinoma in Central Europe: prognostic features and survival. Gut 2001;48 103-109.

18 Bruix J, Sherman M, Llovet JM, Beaugrand M, Lencioni R, Burroughs AK, Christensen E, Pagliaro L, Colombo M, Rodes J: Clinical management of hepatocellular carcinoma: conclusions of the Barcelona-2000 EASL Conference. J Hepatol 2001;35:421-430.

19 Johnson PJ: Hepatocellular carcinoma: is current therapy really altering outcome? Gut 2002;51:459-462.

20 Rabe C, Lenz M, Schmitz V, Pilz T, Fimmers R, Sauerbruch T, Caselmann WH: An independent evaluation of modern prognostic scores in a central European cohort of 120 patients with hepatocellular carcinoma. Eur J Gastroenterol Hepatol 2003;15:1305-1315.

21 Ryder SD, Rizzi PM, Metivier E, Karami J, Williams R: Chemoembolisation with lipiodol and doxorubicin: applicability in British patients with hepatocellular carcinoma. Gut 1996;38:125-128.

22 Sutter AP, Maaser K, Höpfner M, Huether A, Schuppan D, Scherübl H: Cell cycle arrest and apoptosis induction in hepatocellular carcinoma cells by HMG-CoA reductase inhibitors: synergistic antiproliferative action with ligands of the peripheral benzodiazepine receptor. J Hepatol 2005;43:808-816.

23 Weinstein-Oppenheimer CR, HenriquezRoldan CF, Davis JM, Navolanic PM, Saleh OA, Steelman LS, Franklin RA, Robinson PJ McMahon M, McCubrey JA: Role of the Raf signal transduction cascade in the in vitro resistance to the anticancer drug doxorubicin. Clin Cancer Res 2001;7:2898-2907.

24 Banker DE, Mayer SJ, Li HY, Willman CL, Appelbaum FR, Zager RA: Cholesterol synthesis and import contribute to protective cholesterol increments in acute myeloid leukemia cells. Blood 2004;104:1816-1824.
25 Jakobisiak M, Golab J: Potential antitumor effects of statins. Int J Oncol 2003;23:10551069.

26 Li HY, Appelbaum FR, Willman CL, Zager RA, Banker DE: Cholesterol-modulating agents kill acute myeloid leukemia cells and sensitize them to therapeutics by blocking adaptive cholesterol responses. Blood 2003; 101:3628-3634.

27 Kozar K, Kaminski R, Legat M, Kopec M, Nowis D, Skierski JS, Koronkiewicz M, Jakóbisiak M, Golab J: Cerivastatin demonstrates enhanced antitumor activity against human breast cancer cell lines when used in combination with doxorubicin or cisplatin. Int J Oncol 2004;24:1149-1157.

28 Feleszko W, Mlynarczuk I, Balkowiec-Iskra EZ, Czajka A, Switaj T, Stoklosa T, Giermasz A, Jakóbisiak M: Lovastatin potentiates antitumor activity and attenuates cardiotoxicity of doxorubicin in three tumor models in mice. Clin Cancer Res 2000;6:2044-2052.

29 Agarwal B, Bhendwal S, Halmos B, Moss SF, Ramey WG, Holt PR: Lovastatin augments apoptosis induced by chemotherapeutic agents in colon cancer cells. Clin Cancer Res 1999;5:2223-2229.

30 Holstein SA, Hohl RJ: Synergistic interaction of lovastatin and paclitaxel in human cancer cells. Mol Cancer Ther 2001;1:141-149.

31 Bogman K, Peyer AK, Torok M, Kusters E, Drewe J: HMG-CoA reductase inhibitors and P-glycoprotein modulation. Br J Pharmacol 2001;132:1183-1192.

32 Wang E, Casciano CN, Clement RP, Johnson WW: HMG-CoA reductase inhibitors (statins) characterized as direct inhibitors of P-glycoprotein. Pharm Res 2001;18:800806

33 Holmberg M, Sandberg C, Nygren P, Larsson $\mathrm{R}$ : Effects of lovastatin on a human myeloma cell line: increased sensitivity of a multidrugresistant subline that expresses the $170 \mathrm{kDa}$ P-glycoprotein. Anticancer Drugs 1994;5: 598-600.

34 StahlbergD, Rudling M, Angelin B, Björkhem I, Forsell P, Nilsell K, Einarsson K: Hepatic cholesterol metabolism in human obesity. Hepatology 1997;25:1447-1450.

35 Calle EE, Rodriguez C, Walker-Thurmond $\mathrm{K}$, Thun MJ: Overweight, obesity, and mortality from cancer in a prospectively studied cohort of US adults. N Engl J Med 2003;348: 1625-1638.

36 Tatsuta M, Iishi H, Baba M, Iseki K, Yano H, Uehara H, Yamamoto R, Nakaizumi A: Suppression by pravastatin, an inhibitor of p21ras isoprenylation, of hepatocarcinogenesis induced by $\mathrm{N}$-nitrosomorpholine in Sprague-Dawley rats. Br J Cancer 1998;77: 581-587. 